\title{
Neuropsychiatric Adverse Events from Topical Ophthalmic Timolol
}

\author{
Nevio Cimolai, MD, FRCP(C)
}

\begin{abstract}
Timolol is a commonly-used topical antiglaucoma medication and has proven to be highly efficacious for most recipients. Among the reported adverse events, the neuropsychiatric spectrum has been cited, albeit for a small proportion of those treated. This review summarizes the cumulative published experience of such side effects and assesses the quality of evidence. As for other beta-blockers, whether orally or topically administered, various central nervous systems dysfunctions have been detailed in either case reports or larger patient series. The adverse event commonly resolves following drug termination. Rigorous and more definitive studies of causation are lacking, and to some, such paucity has reduced the belief of a cause and effect relationship. Until otherwise proven, deference should be afforded to the potential for topical timolol to cause neuropsychiatric side effects, and at-risk patients should be closely monitored when they are prescribed this pharmacological agent.
\end{abstract}

Keywords: Timolol; Glaucoma; Adverse event; Safety; Topical agent

$\mathrm{T}$ imolol is a beta-adrenergic receptor blocker that was introduced in the late 1970s in both topical and oral formulations. ${ }^{1,2}$ Chemically, it is a propanolamine compound, and is now one of the most common topical treatments for increased intraocular pressure and glaucoma. Its introduction was initially a major innovation, especially for glaucoma treatment. Indeed, the commonly used glaucoma treatments (topical and oral) preceding timolol (eg, pilocarpine, epinephrine, and acetazolamide) were commonly complicated with problematic side effects. ${ }^{3,4}$

Timolol is a non-selective beta-blocker. Its receptor blockade is reversible, but it is nonetheless long-acting. Both topically and systemically, its activity occurs typically in approximately 20 to 30 minutes. In the late 1970 s, it had been already determined that timolol was superior to other beta-blockers for topical glaucoma treatment. ${ }^{3}$ After ocular administration, up to $80 \%$ of the ocular dose can be systemically absorbed through the nasal mucosa. ${ }^{5-7}$ Nevertheless, some $12 \%$ to $88 \%$ of an ocular dose may be lost to eyelid overflow prior to any such absorption. ${ }^{89}$ Over $65 \%$ of peripheral beta-receptors will be saturated through such systemic absorption on an incremental basis. ${ }^{10}$ Cumulative blood levels may reach the range of 0.2 $\mu \mathrm{g} / \mathrm{L}$ to $9 \mu \mathrm{g} / \mathrm{L}$ after the use of either $0.25 \%$ or $0.5 \%$ ophthalmic solutions, but typically blood levels are less than 2 $\mu \mathrm{g} / \mathrm{L} \cdot{ }^{7-10,12,13}$ With a half-life of approximately 5 hours, residual activity persists well past the usual 12-hour dosing interval and possibly up to 24 hours. Peak local pharmacological activity is found after approximately 2 hours. When given orally, timolol is subject to metabolism in a first-pass effect through the liver (up to $40 \%$ ), but such metabolic processing is negligible after ocular administration and nasal absorption., 2,6 Volunteers given an intravenous dose of $0.25 \mathrm{mg}$ have had blood levels comparable to those achieved after topical use. ${ }^{10}$ In contrast, an oral dose of $20 \mathrm{mg}$ (oral dosing usually $10 \mathrm{mg}$ to $20 \mathrm{mg}$ ) will yield plasma levels of approximately $50 \mu \mathrm{g} / \mathrm{L}$ to $100 \mu \mathrm{g} / \mathrm{L}$, although residual plasma levels decreased to approximately $1 \mu \mathrm{g} / \mathrm{L}$ to $7 \mu \mathrm{g} / \mathrm{L} 12$ hours later. ${ }^{11}$ Blood levels 
after ocular administration can remain high among the elderly and among those patients who have metabolic defects for beta-blocker metabolism. ${ }^{10}$ Children often have the higher blood levels. ${ }^{12}$ Ocular timolol can conceivably complicate the existing beta-blockade of other orally administered betablockers. Both topical and systemically absorbed timolol functionally reduce aqueous humor production and, hence, ameliorate glaucoma through a reduced availability of intraocular fluid. Topical timolol applied to one eye is capable of some pressure reduction in the contralateral eye.

Of those given timolol in any topical format, $6 \%$ to $13 \%$ will terminate use for various reasons, albeit mainly ophthalmological. ${ }^{14}$ The magnitude of systemic absorption gives credence to the possibility of early systemic events such as the lowering of blood pressure and reduction of heart rate. ${ }^{3}$ Beta-blockade of a non-selective nature can induce bronchospasm in those so predisposed to reversible airways disease. Soon after topical timolol was introduced for routine use, central nervous system effects were being tallied. ${ }^{3,15}$

\section{Neuropsychiatric Events}

Publications of the association of central nervous system side effects with oral beta-blockers preceded the introduction of timolol by nearly a decade or so. ${ }^{16-21}$ Some of these adverse reactions included depression and psychosis. Citations were also made of such events among human volunteers who were otherwise previously well. ${ }^{19}$ Investigations of the latter led to the proposal that more lipophilic beta-blockers, perhaps with enhanced capacity of entering the central nervous system, could provide a greater risk for neurological events. ${ }^{19}$ The latter concept was disputed by a report in which lipophilic and non-lipophilic beta-blockers induced psychosis in one patient. ${ }^{20} \mathrm{~A}$ better understanding of these concepts regarding lipophilic profile and toxicity is required. Despite the scientific findings, there remains some skepticism about a causal relationship. ${ }^{16}$

When oral timolol was used for hypertensive and cardiac patients, episodes of neuropsychiatric events were also recognized., 2,422 A relationship of increased adverse events with higher blood levels of the drug was suggested. ${ }^{23}$ As reactions to topical timolol became apparent, investigators sought to determine if other topical beta-blockers would pose the same risk. For example, topical timolol was compared to topical betaxolol in several studies, and there were more side effects with the former. ${ }^{24-27}$ Not uncommonly, patients terminated their prescriptions with both oral $(27.8 \%)$ and topical $(9 \%)$ timolol. ${ }^{22,28}$

Table 1 highlights case reports of topical timolol-associated central nervous system events. The patients reported in these publications were considerably heterogeneous. Some had a past history of psychiatric problems. Others were complicated by the use of multiple topical pharmacological agents. A few patients clearly had some cardiac events that may secondarily have caused neurological outfall, as some have suggested. ${ }^{15,41}$
Overall, the side effects disappeared after a few hours to a month, which is consistent with the otherwise general experience of beta-blockers. ${ }^{15,42,43}$ Children of young age are susceptible, although reports are few. ${ }^{12}$ Larger studies of topical timolol for infantile glaucoma are lacking. Few reports have validated the causal relationship by challenge and rechallenge observations. Although the nature of these reports would no doubt raise some limitations about ascribing definitive causation, the timeliness of clinical improvement after drug cessation in most circumstances supports a cause and effect relationship.

The nature of adverse events is detailed in Table 2. ${ }^{2,15,23,28,42,44,45}$ As a non-ocular system category from a National Registry for Drug-Induced Ocular Side Effects, adverse effects of the central nervous system were most commonly reported. ${ }^{44}$ Some patients were unaware of the complications until the medication was stopped. ${ }^{28}$ No association has been found with the use of topical beta-blockers and excess mortality, however. ${ }^{46}$

Larger studies that may be relevant to the understanding of neuropsychiatric complaints or findings are detailed in Table 3. Two studies did not conclude there was an association of topical timolol and central nervous system events. ${ }^{47,48}$ Each of the latter acknowledged the limitations of small patient numbers in the study groups. Several studies are based solely on passive reporting or simple observations, and others were structured as retrospective cohorts. Most, if not all, studies could easily be criticized for one or more limitations. Dosing of topical timolol was not consistently detailed in those reports. Few studies utilized a challenge-rechallenge format. Overall, the level or grade of evidence is not consistent with purposeful, well-designed, randomized studies that could have been inclusive of sufficient patient numbers. ${ }^{52,53}$ Nevertheless, although lacking in many regards of study design and observation, the combination of anecdotes and larger studies could lead one to believe that topical timolol is associated with adverse neuropsychiatric events and that due respect should be afforded to this possibility. A further accumulation of supportive data should be pursued.

Of note, one study of 15 randomized trials of various oral beta-blockers in the realm of cardiology treatments did not find an association of use with the onset of depression, fatigue, or sexual dysfunction. ${ }^{54}$ The latter report, however, preselected for studies where such side effects were reported. Another study of the existing data on topical beta-blockers, and especially timolol, in 2002 also refuted the association with various side effects, but only depression was assessed among illnesses of the neuropsychiatric spectrum. ${ }^{55}$ A major dilemma with the latter approaches, however, was that no systematic prospective studies were then available. Therefore, the clinician is confronted by the refutation of causation based on a lack of data versus the summation of adverse events from general reporting and variable group studies. There is evidently more room for further analyses and hypothesis testing. 


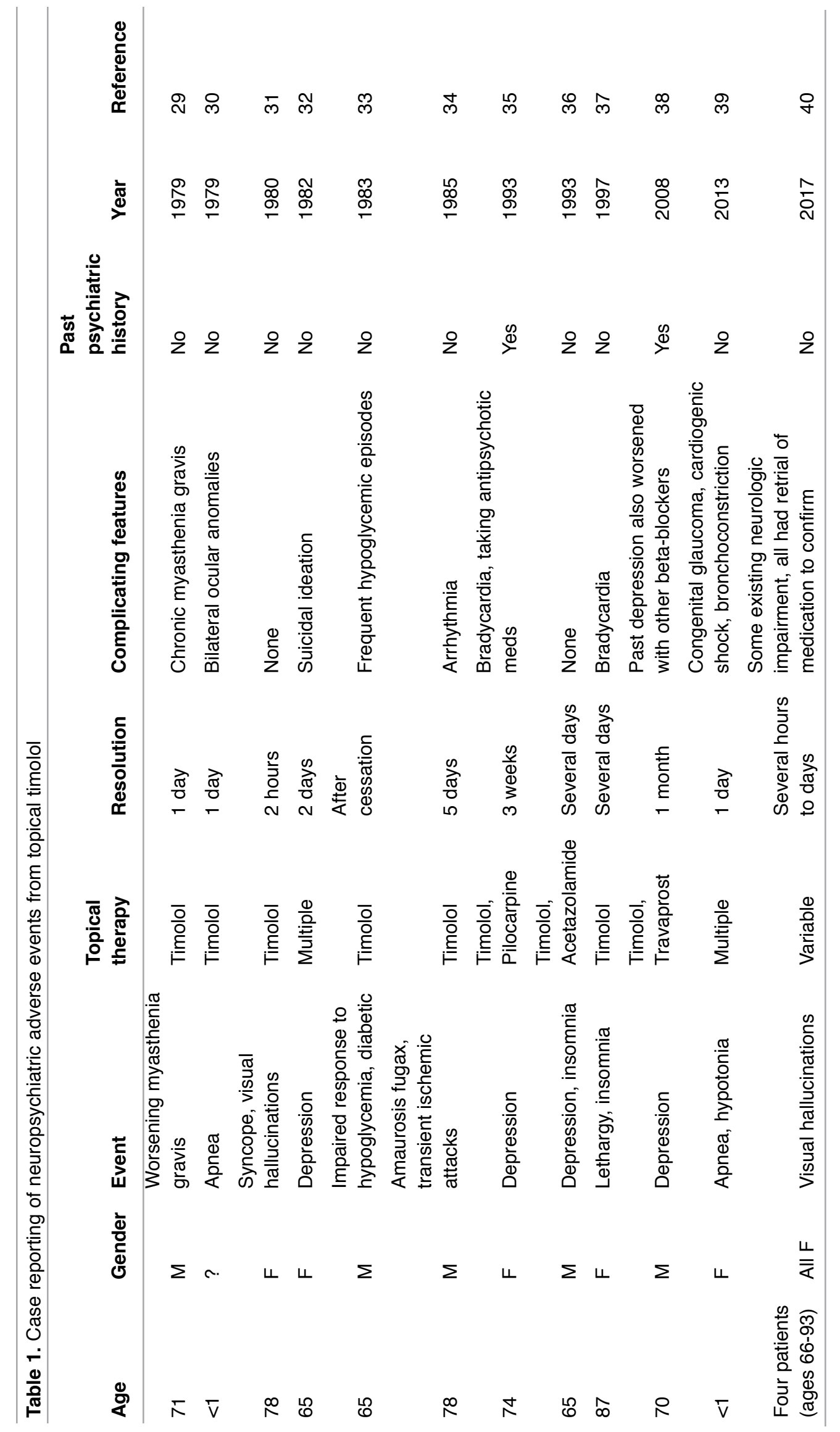


Table 2. Reported adverse reactions that span the neuropsychiatric spectrum

\begin{tabular}{|c|c|}
\hline - Anorexia & - Impotence and other sexual dysfunctions \\
\hline - Anxiety & - Insomnia \\
\hline - Apnea in neonates & - Libido reduction \\
\hline - Confusion & - $\quad$ Lightheadedness \\
\hline - Depression & - Loss of concentration \\
\hline - Diplopia & - $\quad$ Malaise \\
\hline - Disorientation & - $\quad$ Memory loss \\
\hline - Dissociative behavior & - $\quad$ Myalgia \\
\hline - Dizziness & - Myasthenia \\
\hline - Drowsiness & - Nightmares \\
\hline - Dysarthria & - Paresthesia \\
\hline - Dysgeusia & - Peripheral neuropathy \\
\hline - $\quad$ Euphoria & - $\quad$ Sensory disorder \\
\hline - Fatigue & - Somnolence \\
\hline - Hallucinations & - Tinnitus \\
\hline - Headache & - Weakness \\
\hline - Hypotonia & \\
\hline
\end{tabular}

\section{Remnant Concerns}

Could responses to topical timolol be patient specific? Genetic polymorphisms have been linked to beta-blocker efficacy ${ }^{56}$ Can modifications of drug use be applicable? The closure of the nasolacrimal duct after topical administration has been suggested to enhance local penetration. ${ }^{12,57}$ Although the latter might be an appealing tactic to reduce systemic absorption, it is not clear that the neuropsychiatric complications are a function of systemic absorption, penetration of the central nervous system directly through the eye, or any other modality.

It is not uncommon for patients with increased intra-ocular pressure to be elderly. In this patient population, concomitant co-morbidities and frailty generally may confuse the understanding of whether topical timolol is capable of having caused morbidity. When interviewing patients about their drug histories, it is not uncommon for the ophthalmic group to be forgotten in the discussion altogether, and use of topical agents may be overshadowed by other polypharmacy. It is also realistic that physicians will fail to associate a systemic adverse event with a topical ocular solution.

Alterations of topical timolol dosing have not been fully explored. Concerns in this regard parallel the toxicity potential with topical timolol use in pediatric dermatology. ${ }^{58}$ Newer formulations of timolol will undoubtedly exploit sustainedrelease administration or mixed drug formulations. It is unclear at this time how such approaches will affect the frequency of neuropsychiatric events. Timolol is now an old drug, relatively speaking, and yet it is among the most commonly, if not the most commonly, used topical agent in this context. It may prove difficult to stimulate further both molecular and clinical research in its use topically given its lack of novelty and attracted funding.

It would be best to give patients the benefit of doubt when central nervous system effects are being considered. Cautious use of topical timolol in at-risk patients is relevant, and careful observation for neuropsychiatric effects should be maintained. Cessation and sufficient observation or challenge-rechallenge strategies are of potential value in confirming a cause and effect relationship. The increasing spectrum and availability of other topical antiglaucoma agents makes the option of cessation and conversion to another pharmacological agent more available, but the issue of adverse events will continue into the foreseeable future given the continuing high frequency of topical timolol use in glaucoma.

\section{References}

1. Editor. Timolol maleate - a new drug for glaucoma. Med Lett 1978;20(520):109-110.

2. Editor. Timolol for hypertension. Med Lett 1982;24(608):44-46.

3. Kosman ME. Timolol in the treatment of open angle glaucoma. JAMA. 1979;241(21):2301 2303.

4. Zimmerman TJ, Baumann JD, Hetherington J Jr. Side effects of timolol. Surv Ophthalmol. 1983;28 Suppl:243-251. 


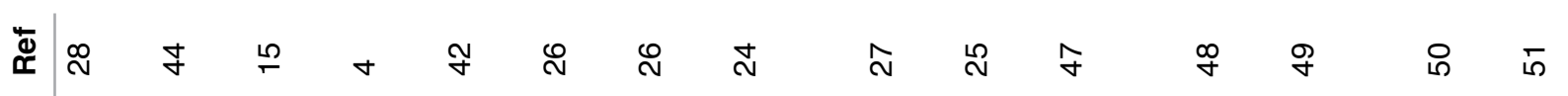

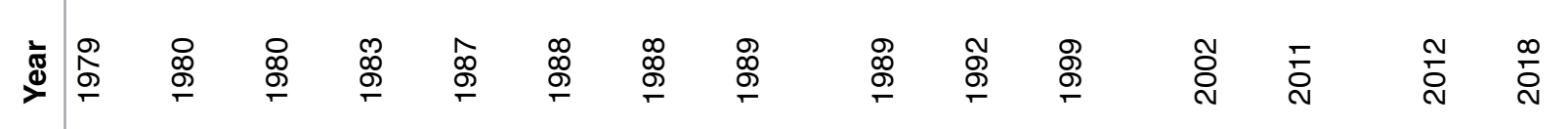

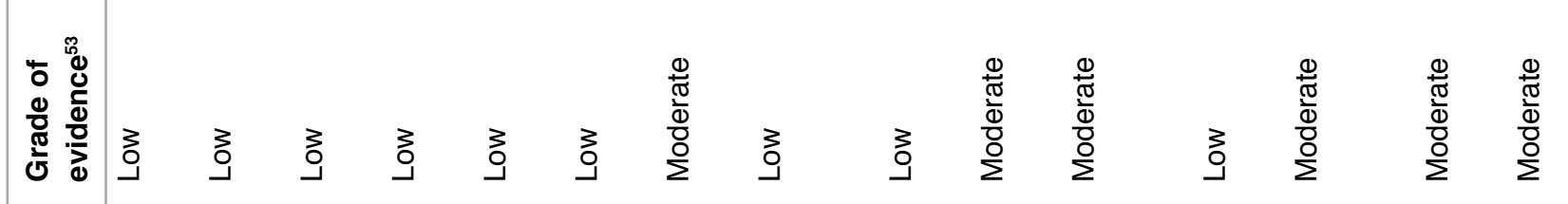

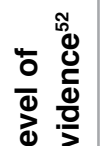

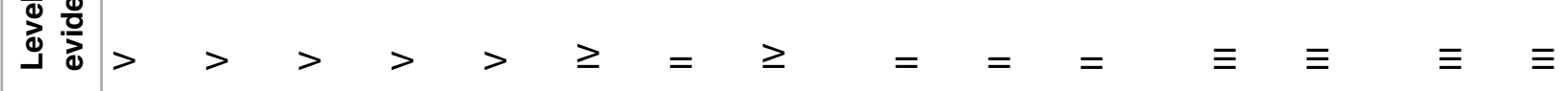

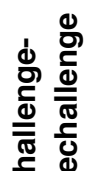

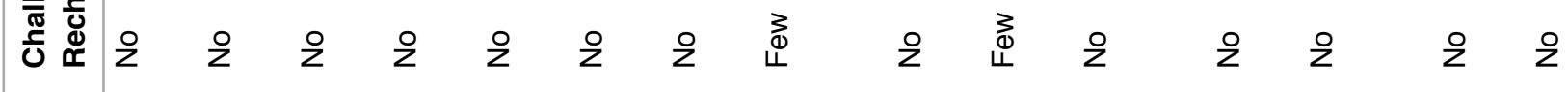

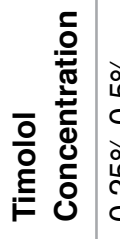

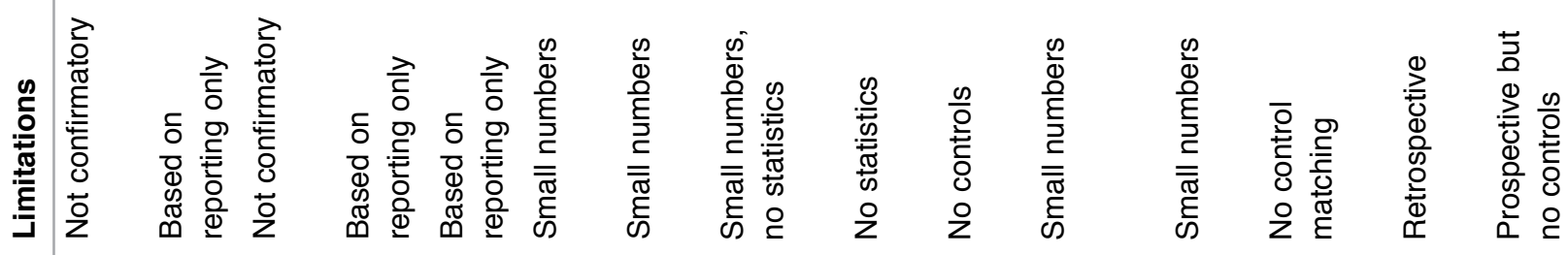

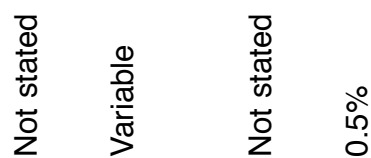

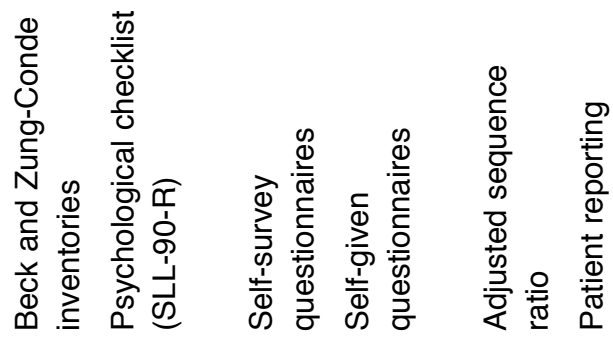

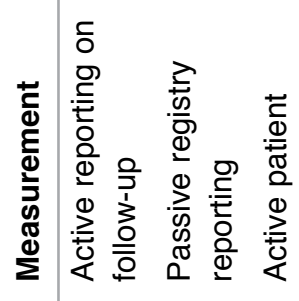

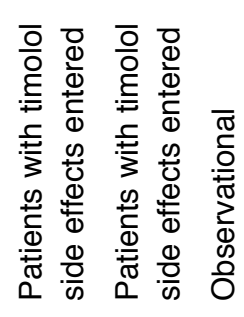

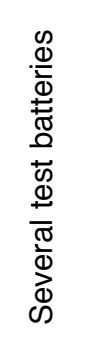

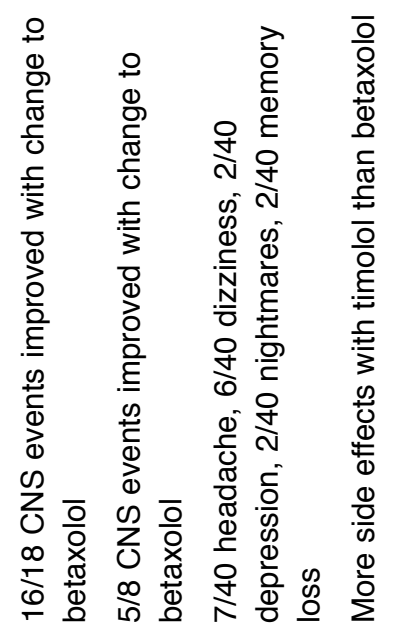

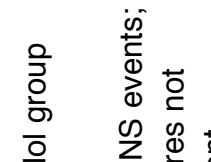

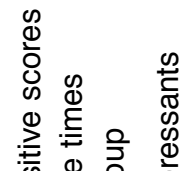

N $\sum_{0}^{\infty} \frac{\frac{c}{\omega}}{\frac{\pi}{\pi}}$

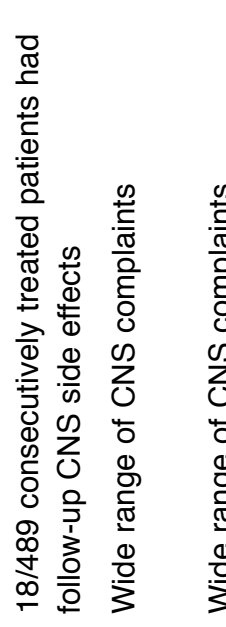

势

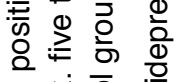

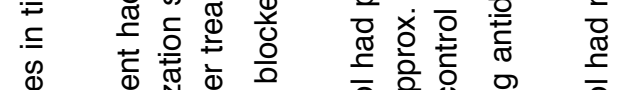

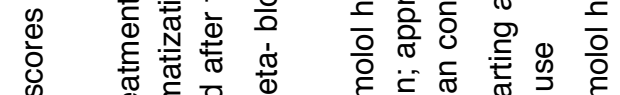

等

음 엉

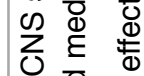

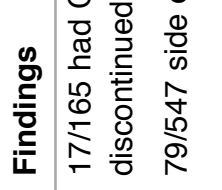

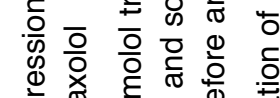

5

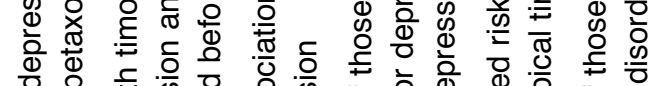

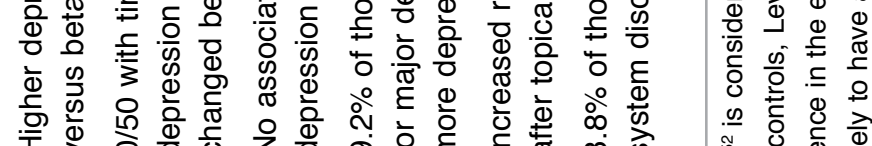
I

然客 
5. Shell JW. Pharmacokinetics of topically applied ophthalmic drugs. Surv Ophthalmol. 1982;26(4):207-218.

6. Fraunfelder FT. Ocular beta-blockers and systemic effects. Arch Intern Med. 1986;146(6):1073-1074.

7. Korte JM, Kaila T, Saari KM. Systemic bioavailability and cardiopulmonary effects of $0.5 \%$ timolol eyedrops. Graefes Arch Clin Exp Ophthalmol. 2002;240(6):430-435.

8. Alvan G, Calissendorff B, Seideman P, Widmark K, Widmark G. Absorption of ocular timolol. Clin Pharmacokinet. 1980;5(1):95-100.

9. Affrime MB, Lowenthal DT, Tobert JA, et al. Dynamics and kinetics of ophthalmic timolol. Clin Pharmacol Ther. 1980;27(4):471-477.

10. Vuori ML, Kaila T. Plasma kinetics and antagonist activity of topical ocular timolol in elderly patients. Graefes Arch Clin Exp Ophthalmol. 1995;233(3):131-134.

11. Fourtillan JB, Courtois P, Lefebvre MA, Girault J. Pharmacokinetics of oral timolol studied by mass fragmentography. Eur J Clin Pharmacol. 1981;19(3):193196.

12. Passo MS, Palmer EA, Van Buskirk EM. Plasma timolol in glaucoma patients. Ophthalmology. 1984;91(11):1361-1363.

13. Kaila T, Salminen L, Huupponen R. Systemic absorption of topically applied ocular timolol. J Ocul Pharmacol Ther. 1985;1(1):79-83.

14. Beckers HJ, Schouten JS, Webers CA, van der Valk R, Hendrikse F. Side effects of commonly used glaucoma medications: comparison of tolerability, chance of discontinuation, and patient satisfaction. Graefes Arch Clin Exp Ophthalmol. 2008;246(10):1485-1490.

15. Wilson RP, Spaeth GL, Poryzees E. The place of timolol in the practice of ophthalmology. Ophthalmology. 1980;87(5):451454.

16. Ried LD, McFarland BH, Johnson RE, Brody KK. Betablockers and depression: the more the murkier? Ann Pharmacother. 1998;32(6):699-708.

17. Waal HJ. Propranolol-induced depression. BMJ. 1967;2(5543):50.

18. Gershon ES, Goldstein RE, Moss AJ, van Kammen DP. Psychosis with ordinary doses of propranolol. Ann Intern Med. 1979;90(6):938-939

19. Bourgeois JA. Depression and topical ophthalmic beta adrenergic blockade. J Am Optom Assoc. 1991;62(5):403406.

20. Sklar SJ, Huck LA. Possible association of nonlipophilic betablockers and acute psychosis. Clin Pharm. 1983;2(3):274277.

21. Greenblatt DJ, Shader RI. On the psychopharmacology of beta adrenergic blockade. Curr Ther Res Clin Exp. 1972;14(9):615-625.

22. Bannon JA, Stewart KA, DeLisser O, Schrogie JJ. Clinical experience with timolol maleate monotherapy of hypertension. Arch Intern Med. 1986;146(4):654-657.

23. Zimmerman TJ, Leader BJ, Golob DS. Potential side effects of timolol therapy in the treatment of glaucoma. Ann Ophthalmol. 1981;13(6):683-689.

24. de Vries J, van de Merwe SA, Jan de Heer L. From timolol to betaxolol. Arch Ophthalmol. 1989;107(5):634.

25. Duch S, Duch C, Pastó L, Ferrer P. Changes in depressive status associated with topical beta-blockers. Int Ophthalmol. 1992;16(4-5):331-335.

26. Lynch MG, Whitson JT, Brown RH, Nguyen H, Drake MM. Topical beta-blocker therapy and central nervous system side effects. A preliminary study comparing betaxolol and timolol. Arch Ophthalmol. 1988;106(7):908-911.

27. Cohen JB. A comparative study of the central nervous system effects of betaxolol vs timolol. Arch Ophthalmol. 1989; 107(5):633-634.
28. McMahon CD, Shaffer RN, Dunbar Hoskins HD Jr, Hetherington J Jr. Adverse effects experienced by patients taking timolol. Am J Ophthalmol. 1979;88(4):736-738.

29. Shaivitz SA. Timolol and myasthenia gravis. JAMA. 1979;242(15):1611-1612.

30. Olson RJ, Britt Bromberg B, Zimmerman TJ. Apneic spells associated with timolol therapy in a neonate. Am J Ophthalmol. 1979;88(1):120-122.

31. Yates D. Syncope and visual hallucinations, apparently from timolol. JAMA. 1980;244(8):768-769.

32. Nolan BT. Acute suicidal depression associated with use of timolol. JAMA. 1982;247(11):1567.

33. Velde TM, Kaiser FE. Ophthalmic timolol treatment causing altered hypoglycemic response in a diabetic patient. Arch Intern Med. 1983;143(8):1627.

34. Coppeto JR. Transient ischemic attacks and amaurosis fugax from timolol. Ann Ophthalmol. 1985;17(1):64-65 .

35. Rao MR, O'Brien J, Dening TR, Dober M. Systemic hazards of ocular timolol. Br J Hosp Med. 1993;50(9):553.

36. Kurtz S, Ashkenazi I, Melamed S. Major depressive episode secondary to antiglaucoma drugs. Am J Psychiatry. 1993;150(3):524-525.

37. Vahidassr MD, Foy CJ, O'malley T, Passmore AP. Eye drops and lethargy. J R Soc Med. 1997;90(3):155.

38. Schweitzer I, Maguire K, Ng CH. A case of melancholic depression induced by beta-blocker antiglaucoma agents. Med J Aust. 2008;189(7):406-407.

39. Kiryazov K, Stefova M, Iotova V. Can ophthalmic drops cause central nervous system depression and cardiogenic shock in infants? Pediatr Emerg Care. 2013;29(11):1207-1209.

40. Nanda T, Rasool N, Callahan AB, Stamper RL, Odel JG. Ophthalmic timolol hallucinations: a case series and review of the literature. J Glaucoma. 2017;26(9):e214-e216.

41. Adler AG, McElwain GE, Merli GJ, Martin JH. Systemic effects of eye drops. Arch Intern Med. 1982;142(13):22932294.

42. Shore JH, Fraunfelder FT, Meyer SM. Psychiatric side effects from topical ocular timolol, a beta-adrenergic blocker. J Clin Psychopharmacol. 1987;7(4):264-267.

43. Trawick AB. Potential systemic and ocular side effects associated with topical administration of timolol maleate. $\mathrm{J}$ Am Optom Assoc. 1985;56(2):108-112.

44. van Buskirk EM. Adverse reactions from timolol administration. Ophthalmology. 1980;87(5):447-450.

45. Fraunfelder FT, Meyer SM. Sexual dysfunction secondary to topical ophthalmic timolol. JAMA. 1985;253(21):3092-3093.

46. Müskens RP, Wolfs RC, Witteman JC, et al. Topical betablockers and mortality. Ophthalmology. 2008;115(11):20372043.

47. Bartlett JD, Olivier M, Richardson T, Whitaker R Jr, Pensyl D, Wilson MR. Central nervous system and plasma lipid profiles associated with carteolol and timolol in postmenopausal black women. J Glaucoma. 1999;8(6):388-395.

48. Wilson MR, Coleman AL, Yu F, Fong Sasaki I, Bing EG, Kim MH. Depression in patients with glaucoma as measured by self-report surveys. Ophthalmology. 2002;109(5):1018-1022.

49. Bali SJ, Parmar T, Arora V, Ichhpujani P, Sagar R, Dada T. Evaluation of major depressive disorder in patients receiving chronic treatment with topical timolol. Ophthalmologica. 2011;226(3):157-160.

50. Roughead EE, Kalisch LM, Pratt NL, Killer G, Barnard A, Gilbert AL. Managing glaucoma in those with co-morbidity: not as easy as it seems. Ophthalmic Epidemiol. 2012;19(2):74 82.

51. Serle JB, Katz LJ, McLaurin E, et al. Two phase 3 clinical trials comparing the safety and efficacy of netarsudil to timolol in patients with elevated intraocular pressure: Rho kinase elevated IOP treatment trial 1 and 2 (ROCKET- 1 and ROCKET-2). Am J Ophthalmol. 2018;186:116-127. 
52. Sackett DL. Rules of evidence and clinical recommendations on the use of antithrombotic agents. Chest. 1989;95(2 Suppl):2S$4 \mathrm{~S}$.

53. Atkins D, Best D, Briss PA, et al. Grading quality of evidence and strength of recommendations. BMJ. 2004;328(7454):1490.

54. Ko DT, Hebert PR, Coffey CS, Sedrakyan A, Curtis JP, Krumholz HM. Beta-blocker therapy and symptoms of depression, fatigue, and sexual dysfunction. JAMA. 2002;288(3):351-357.

55. Lama PJ. Systemic adverse effects of beta-adrenergic blockers: an evidence-based assessment. Am J Ophthalmol. 2002;134(5):749-760.

56. Shin J, Johnson JA. Pharmacogenetics of beta-blockers. Pharmacotherapy. 2007;27(6):874 887.

57. Zimmerman TJ, Kooner KS, Kandarakis AS, Ziegler LP. Improving the therapeutic index of topically applied ocular drugs. Arch Ophthalmol. 1984;102(4):551-553.

58. Dalla Costa R, Prindaville B, Wiss K. Doing the math: A simple approach to topical timolol dosing for infantile hemangiomas. Pediatr Dermatol. 2018;35(2):276-277.

\section{Author Affiliations}

Nevio Cimolai $M D$, FRCP $(C) *+$

*Department of Pathology and Laboratory Medicine, Faculty of Medicine, The University of British Columbia, Vancouver, British Columbia, Canada

†Department of Pathology and Laboratory Medicine,

Children's and Women's Health Centre of British Columbia,

Vancouver, British Columbia, Canada 